www.jmscr.igmpublication.org

Impact Factor 5.84

Index Copernicus Value: 71.58

ISSN (e)-2347-176x ISSN (p) 2455-0450

crossref DOI: _https://dx.doi.org/10.18535/jmscr/v5i12.84

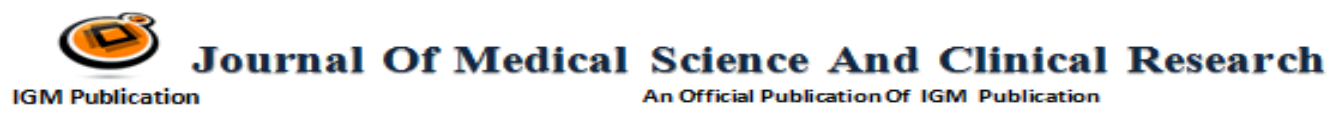

\title{
External Validation of PCOS Questionnaire in Assessing Quality of Life in Females with PCOS Based on Lifestyle Changes with Therapeutic Measures like OC Pills and Metformin
}

\section{Priyanka Routray $^{1}$, Basant K Pati ${ }^{2 *}$, Mahesh Chandra Sahu ${ }^{3}$}

${ }^{1}$ MBBS Student, IMS \& SUM Hospital, SOA University, K8, Kalinga Nagar, Bhubaneswar-751003, Odisha, India

${ }^{2}$ Associate Professor, Department of Obstetrics and Gynaecology, IMS \& SUM Hospital, SOA University, K8, Kalinga Nagar, Bhubaneswar-751003, Odisha, India

${ }^{3}$ Assistant Professor, Directorate of Medical Research, IMS \& SUM Hospital, SOA University, K8, Kalinga Nagar, Bhubaneswar-751003, Odisha, India

Corresponding Author*

\section{Dr Basanta Kumar Pati}

Associate Professor, Department of Obstetrics and Gynaecology, IMS \& SUM Hospital, Bhubaneswar,

Email:drbasantapati@gmail.com

\section{Abstract}

Background: The aim was to study the effect of metformin in a lifestyle modification program combined with oral contraceptive pills on quality of life parameters measured by PCOS questionnaire in women and validate PCOSQ.

Methodology: Total 50 willing patients with PCOS participated in this hospital based single centered pilot study. Patients had to rate the symptoms given in questionnaire concerning health and health related issues on a scale of 1-7. Random selection for treatment with OC pills with or without Metformin was made. Post treatment analysis of their quality of life was done with the same questionnaire and data was analyzed by SPS statistical software.

Result: The patients taking metformin along with OC Pills showed significant improvement in menstrual irregularities, hirsutism and the psychological distress related to it. Neither the symptoms related to being overweight was improved significantly nor the Psychological and emotional conditions regarding the symptoms. Similar results were obtained when we compared pre and post therapy scores in patients taking placebo in place of metformin.

Conclusion: This study validated the PCOS questionnaire in Indian population which can be considered first of its kind. This can give us an objective method of response assessment in patients with PCOS and also showed no significant additional effect of metformin on improvement of symptoms in patients with PCOS, which could be secondary to either small sample size or short duration of action.

Keywords: Metformin, PCOS, hirsutism, acne, HRQL, Health-related quality of life, Overweight.

\section{Introduction}

Polycystic ovarian syndrome (PCOS) is one of the most common reproductive endocrinological disorders affecting about 6-8\% of women in their reproductive years ${ }^{1}$. Although there are limited studies in India, recently few studies reported 
prevalence of PCOS ranging from $9.13 \%$ to $36 \%$ among adolescents ${ }^{2}$. PCOS is a heteroge-neous condition with varied signs and symptoms that include amenorrhoea, oligomenorrhoea, hirsutism, obesity, subfertility, anovulation and acne. Any of these symptoms can significantly affect the female's quality of life $^{3}$. The greatest negative influences on quality of life were associated with hirsutism (especially under the age of 25 years old), being overweight, and infertility concerns (over age 25$)^{4}$. Usually signs and symptoms of the disorder appear at puberty, however it may not be diagnosed until adulthood in some. ${ }^{5}$ PCOS accounts for $95 \%$ of cases of hyperandrogenism, $20 \%$ of all cases of amenorrhea and up to $75 \%$ of all cases of anovulatory infertility ${ }^{6}$. The treatment of PCOS proves to be effective if it can reduce the burden of these symptoms as well as the associated psychological distress and thus improve health-related quality of life (HRQL).

It is found that mostly PCOS is the endocrine disorder in reproductive-aged women ${ }^{7}$. There are several clinical presentations associated with PCOS, such as hirsutism, acne, overweight/obesity, hair loss/ androgenic alopecia, oligomenorrhea, amenorrhea and infertility and can lead to mood disturbances, affect the emotional wellbeing as well as sexual satisfaction of women, and cause a reduction in the HRQoL of patients ${ }^{8,9}$. Obesity, clinical signs of hyperandrogenism (i.e., acne, hair loss), and infertility are the main contributors to psychological morbidity ${ }^{10-12}$. The HRQoL of women with PCOS has been investigated in several studies for some countries ${ }^{8,13,14}$; however, data on the HRQL of Indian women with PCOS is limited. It has been recognized that clinical representations of PCOS vary with culture and ethnicity $^{15}$, and may thus have different impacts on HRQL. For example, the prevalence of hirsutism and obesity in Chinese women with PCOS appears to be lower than that from Caucasians patients ${ }^{15}$; contrarily, acne and hair loss were common problems reported in ethnic Chinese women with $\operatorname{PCOS}^{16}$. Therefore, assessing the impact of PCOS on the HRQL of patients across ethnic groups is important. Metformin, which increases insulin sensitivity, is one of common treatments for PCOS in Taiwan. Some studies showed that metformin decreases the body weight and improves insulin sensitivity, acne, hirsutism, and menstrual cycle of women with PCOS, and that the effects of metformin may vary depending on a patient's characteristics (i.e., obesity, hyperandrogenism) ${ }^{17-20}$. However, other research found that, among obese women with PCOS, metformin may not lower body weight or improve the menstrual cycle and weight loss alone through lifestyle modifications improves menstrual function ${ }^{21}$. Of notice, previous research primarily focused on clinical effectiveness of metformin ${ }^{17,21}$, but only a few studies ${ }^{8,22}$ have determined whether the amelioration of the clinical signs of PCOS achieved by treatment leads to improvement in the HRQL of patients.

Till date, no study has been done among the Indian population regarding effects on psychological or emotional well-being after therapeutic interventions. There is paucity of data regarding the role of lifestyle modification and therapeutic interventions in emotional well being of females with PCOS An examination of the effect of treatment on quality of life in this, could provide additional insight into the appropriate treatment course. The PCOS questionnaire, validated for its use as a reliable instrument for measuring the HRQL in women with PCOS, requires an external validation due to ethnic variation in PCOS and lower BMI cut off in Indian women. So we are investigating the quality of life factors in Indian women with PCOS using the PCOS Questionnaire (PCOSQ) during a randomized trial of metformin or placebo, with concurrent LSM and OC treatment in deciding the therapeutic intervention in Indian women with PCOS, which will help to individualize the treatment protocol.

\section{Materials \& Methods \\ Identification of patient population}

The study was conducted after getting clearance from the institutional ethical committee. Total 
number of subjects recruited was 50 with 25 subjects in each treatment arm. Medical students, nursing students and patients from the department with PCOS who were willing to participate were recruited. Written informed consent from the patients was obtained before recruiting them.

\section{Type of study}

It was a prospective hospital based single centered interventional trial with follow up period of 2 months.

\section{Women with PCOS who met following criteria were included}

1. Women of reproductive age group (Age: $18-45$ yrs)

2. Hyperandrogenism, elevation of total testosterone, moderate to severe facial hirsutism and/ or terminal hair growth on upper chest, back and infraumblical area

3. Menstrual irregularities-oligomenorrhoea: menses every 6 weeks -6 months Amenorrhoea DUB (dysfunctional uterine bleeding) with documented anovulation

\section{Women with following criteria were excluded}

1) Diagnosis of hyperprolactinemia, non classical -21 hydroxylase deficiency

2) Linguistic or cognitive difficulties preventing reliable completion of the questionnaire

The demographic profile of involved patients was collected before drug intervention.

This includes year of birth, marital status, educational qualification, BMI and duration of PCOS and the frequency of each parameter is provided (Fig 1- Fig 4, Table 1).

Height, weight and BMI of all the patients obese or non obese.

\section{Method of Randomization}

Sealed opaque random codes by block method

\section{Method of Allocation Concealment}

Sealed opaque envelopes were used for allocation of the randomization sequences, which was opened after consent. Patients included in this trial were given the questionnaire concerning health and health related issues. The PCOSQ developed by Cronin et $\mathrm{al}^{11}$ for the assessment of healthrelated quality-of- life (HRQL) consists of five domains, each relating to the common symptoms of PCOS-pattern of hair growth on face and body, emotions, infertility, menstrual problems and weight. Patients rated the symptoms on a scale of $1-7$, in accordance with the PCOSQ with 7 being worst (symptoms all of the time) and 1 best (symptoms none of the time). Questions were self administered and given in their own vernacular language. The questionnaire was administered and supervised by a single principal investigator. Questions were compiled and assessment of the quality of life was done. Patients were randomly selected in either OC pills with or without Metformin. Placebo was supplied to the patients with OC pills without metformin by our registered pharmacy. Menstrual data and pill counts of the subjects were collected by personal visit to the hospital. A proper diet chart was provided to the subjects by the registered dietician of our institute. Patients were encouraged to exercise for 20- 30 minutes per day of moderate-to-intense physical activity. Post treatment analysis of their quality of life was done with similar questionnaire. Data was analyzed by SPSS statistical software .The differences in mean scores were compared between groups by unpaired t-test and differences in means between pre and post therapy scores in a single group were analyzed by using paired t-test.

\section{Result}

Out of 50 patients recruited, 2 patients from placebo group didn't turn up for follow up and one patient from metformin group excluded due to lack of compliance. When we compared the effect of OC pills with metformin/ placebo on the 47 patients enrolled for the study, total scores of PCOSQ improved across almost all the domains, suggesting significant improvement in quality of life after treatment. We also tried to compare the pre and post therapy improvement in scores of symptoms separately in two randomized groups. As per table 2, the patients taking metformin along with OC Pills showed significant improvement in menstrual irregularities. Presence of visible hair on chin, upper lips and the psychological distress related to it have also 
improved significantly after metformin treatment (Table 2). However there in no significant improvement in the symptoms related to being overweight. Psychological and emotional conditions regarding the symptoms haven't changed significantly after the therapeutic intervention. Similar results were obtained when we compared pre and post therapy scores in patients taking placebo in place of metformin. This showed most of the symptoms got improved significantly after treatment (Table 3 ). However in both the groups the confounding factor being the OC pills, we tried to compare the post intervention symptom scores among both the groups
(Metformin and placebo) directly. This is to show whether there is any additional statistically significant effect of metformin on improvement on quality of life or not. On analysis, as in table 4, it showed there is no significant difference in post symptom score improvement in any of the symptoms after therapeutic intervention (Table 4)

Table 1 Duration of PCOS symptoms of the patients attending during the study period

\begin{tabular}{|l|c|c|}
\hline Sl. No. & Duration of PCOS & Number of patients \\
\hline 1 & Less than $1 \mathrm{yr}$ & 23 \\
\hline 2 & $1-5$ yrs & 19 \\
\hline 3 & $>5$ years & 8 \\
\hline
\end{tabular}

Table 2 Statistical significance of the effect of OC pills with metformin on PCOS patients.

\begin{tabular}{|c|c|c|c|c|}
\hline Sl. No. & SYMPTOMS & $\begin{array}{c}\mathrm{MEAN} \pm \mathrm{SD} \\
\mathrm{BEFORE} \\
\text { MEDICATION }\end{array}$ & $\begin{array}{c}\text { MEAN }+ \text { SD } \\
\text { AFTER } \\
\text { MEDICATION }\end{array}$ & P VALUE \\
\hline 1. & Growth of visible hair on chin & $4.25 \pm 1.85$ & $3.83 \pm 1.49$ & 0.005 \\
\hline 2. & Depressed as a result of having pcos & $4.71 \pm 1.16$ & $4.17 \pm 1.13$ & 0.012 \\
\hline 3. & Concerned about being overweight & $4.50 \pm 1.72$ & $4.04 \pm 1.52$ & 0.036 \\
\hline 4. & Easily tired & $4.75 \pm 1.33$ & $4.00 \pm 1.14$ & 0.000 \\
\hline 5. & Corcerned with infertility problems & $4.04+1.65$ & $3.46 \pm 1.44$ & 0.001 \\
\hline 6. & Moody as a result of having pcos & $4.29 \pm 1.43$ & $3.79 \pm 1.25$ & 0.007 \\
\hline 7. & Headaches & $3.88 \pm 1.42$ & $3.63 \pm 1.35$ & 0.083 \\
\hline 8. & Irregular menstruation & $4.96+1.46$ & $3.83+1.31$ & 0.001 \\
\hline 9. & Growth of visible hair on upper lip & $4.63 \pm 1.50$ & $3.88 \pm 1.23$ & 0.009 \\
\hline 10. & Had trouble dealing with your weight & $4.63 \pm 1.69$ & $4.17 \pm 1.55$ & 0.069 \\
\hline 11. & Had low self esteem as aresult of having your pcos & $4.17 \pm 1.20$ & $4.04 \pm 1.16$ & 0.450 \\
\hline 12. & Felt frustration in trying to loose weight & $4.42 \pm 1.47$ & $4.21+1.53$ & 0.233 \\
\hline 13. & Felt afraid of not being able to have children & $3.88 \pm 1.78$ & $3.38 \pm 1.58$ & 0.015 \\
\hline 14. & Felt frightened of getting cancer & $3.21+1.44$ & $3.04 \pm 1.04$ & 0.405 \\
\hline 15. & Growth of visible hairon your face & $4.50 \pm 1.59$ & $3.79 \pm 1.44$ & 0.000 \\
\hline 16. & Embarrassment about excessive body hair & $4.04 \pm 1.46$ & $3.38 \pm 1.31$ & 0.000 \\
\hline 17. & Worried about having pcos & $4.71 \pm 1.20$ & $4.04 \pm 1.23$ & 0.000 \\
\hline 18. & Self conscious as a result of having pcos & $4.29 \pm 1.37$ & $3.88 \pm 1.08$ & 0.116 \\
\hline 19. & Abdominal bloating & $4.21 \pm 1.25$ & $3.79 \pm 1.14$ & 0.067 \\
\hline 20. & Late menstrual periods & $4.92+1.72$ & $3.67 \pm 1.31$ & 0.000 \\
\hline 21. & Menstrual cramps & $4.21 \pm 1.77$ & $3.71 \pm 1.49$ & 0.043 \\
\hline 22. & Feel like you are not sexy because of being overweight & $4.00 \pm 1.53$ & $3.88 \pm 1.65$ & 0.479 \\
\hline 23. & Feel a lack of control over the situation with PCOS & $4.17 \pm 1.46$ & $4.00 \pm 1.32$ & 0.382 \\
\hline 24. & Have difficulties staying at your ideal weight & $4.58 \pm 1.59$ & $4.17 \pm 1.46$ & 0.022 \\
\hline 25. & Feel sad because of infertility problems & $3.88 \pm 1.73$ & $3.46 \pm 1.38$ & 0.096 \\
\hline 26. & Growth of visible body hair & $4.38+1.66$ & $4.00 \pm 1.18$ & 0.119 \\
\hline
\end{tabular}

Table 3 Statistical significance of the effect of OC pills with placebo on PCOS patients

\begin{tabular}{|c|l|c|c|c|}
\hline Sl. No. & SYMPTOMS & $\begin{array}{c}\text { MEAN } \pm \text { SD } \\
\text { BEFORE } \\
\text { MEDICATION }\end{array}$ & $\begin{array}{c}\text { MEAN } \pm \text { SD } \\
\text { AFTER } \\
\text { MEDICATION }\end{array}$ & $\begin{array}{c}\text { P } \\
\text { VALUE }\end{array}$ \\
\hline 1. & Growth of visible hair on chin & $3.65 \pm 1.50$ & $3.26 \pm 1.32$ & 0.004 \\
\hline 2. & Depressed as a result of having PCOS & $3.87 \pm 1.36$ & $3.57 \pm 1.16$ & 0.216 \\
\hline 3. & Concerned about being overweight & $4.35 \pm 1.58$ & $3.78 \pm 1.38$ & 0.000 \\
\hline 4. & Easily tired & $4.04 \pm 1.40$ & $3.43 \pm 1.24$ & 0.000 \\
\hline 5. & Concerned with infertility problems & $3.91 \pm 1.76$ & $3.52 \pm 1.56$ & 0.119 \\
\hline
\end{tabular}




\begin{tabular}{|c|l|c|c|c|}
\hline 6. & Moody as a result of having PCOS & $4.35 \pm 1.34$ & $3.65 \pm 1.23$ & 0.000 \\
\hline 7. & Headaches & $3.74 \pm 1.21$ & $3.48 \pm 1.16$ & 0.186 \\
\hline 8. & Irregular menstruation & $5.13 \pm 1.10$ & $3.91 \pm 1.56$ & 0.000 \\
\hline 9. & Growth of visible hair on upper lip & $4.26 \pm 1.48$ & $3.61 \pm 1.47$ & 0.013 \\
\hline 10. & Had trouble dealing with your weight & $4.17 \pm 1.56$ & $3.70 \pm 1.33$ & 0.024 \\
\hline 11. & $\begin{array}{l}\text { Had low self esteem as a result of having your } \\
\text { PCOS }\end{array}$ & $3.87 \pm 1.58$ & $3.52 \pm 1.34$ & 0.029 \\
\hline 12. & Felt frustration in trying to loose weight & $4.04 \pm 1.49$ & $3.57 \pm 1.41$ & 0.018 \\
\hline 13. & Felt afraid of not being able to have children & $3.87 \pm 1.66$ & $3.22 \pm 1.41$ & 0.001 \\
\hline 14. & Felt frightened of getting cancer & $3.57 \pm 1.38$ & $3.17 \pm 1.19$ & 0.095 \\
\hline 15. & Growth of visible hair on your face & $4.04 \pm 1.49$ & $3.13 \pm 1.14$ & 0.000 \\
\hline 16. & Embarrassment about excessive body hair & $3.74 \pm 1.48$ & $3.09 \pm 1.12$ & 0.025 \\
\hline 17. & Worried about having PCOS & $4.13 \pm 1.10$ & $3.39 \pm 1.12$ & 0.000 \\
\hline 18. & Self conscious as a result of having PCOS & $4.17 \pm 1.15$ & $3.52 \pm 1.12$ & 0.001 \\
\hline 19. & Abdominal bloating & $3.70 \pm 1.55$ & $3.17 \pm 1.15$ & 0.056 \\
\hline 20. & Late menstrual periods & $4.74 \pm 1.10$ & $3.87 \pm 1.29$ & 0.004 \\
\hline 21. & Menstrual cramps & $3.87 \pm 1.55$ & $3.35 \pm 1.19$ & 0.004 \\
\hline 22. & Feel like you are not sexy because of being & $3.74 \pm 1.36$ & $3.35 \pm 1.37$ & 0.165 \\
\hline 23. & Feel a lack of control over the situation with & $4.13 \pm 1.46$ & $3.48 \pm 1.12$ & 0.006 \\
\hline & PCOS & & & \\
\hline 24. & Have difficulties staying at your ideal weight & $4.04 \pm 1.33$ & $3.61 \pm 1.16$ & 0.171 \\
\hline 25. & Feel sad because of infertility problems & $3.70 \pm 1.61$ & $3.39 \pm 1.31$ & 0.110 \\
\hline 26. & Growth of visible body hair & $4.23 \pm 1.45$ & $3.39 \pm 1.34$ & 0.003 \\
\hline
\end{tabular}

Table 4 statistical analysis of the scores achieved in both the groups after therapeutic intervention

\begin{tabular}{|c|c|c|c|c|}
\hline S1 No. & SYMPTOMS & $\begin{array}{l}\text { MEAN +SD OF } \\
\text { GROUP A AFTER } \\
\text { MEDICATION }\end{array}$ & $\begin{array}{l}\text { MEAN +SD OF } \\
\text { GROUP B AFTER } \\
\text { MEDICATION }\end{array}$ & $\begin{array}{c}\text { P } \\
\text { VALUE }\end{array}$ \\
\hline 1. & Growth of visible hair on chin & $3.83+1.49$ & $3.26+1.32$ & 0.178 \\
\hline 2. & Depressed as a result of having pcos & $4.17+1.13$ & $3.57+1.16$ & 0.178 \\
\hline 3. & Concerned about being overweight & $4.04+1.52$ & $3.78+1.38$ & 0.622 \\
\hline 4. & Easily tired & $4.00+1.14$ & $3.43+1.24$ & 0.137 \\
\hline 5. & Corcerned with infertility problems & $3.46+1.44$ & $3.52+1.56$ & 0.567 \\
\hline 6. & Moody as a result of having pcos & $3.79+1.25$ & $3.65+1.23$ & 0.665 \\
\hline 7. & Headaches & $3.63+1.35$ & $3.48+1.16$ & 0.714 \\
\hline 8. & Irregular menstruation & $3.83+1.31$ & $3.91+1.56$ & 0.528 \\
\hline 9. & Growth of visible hair on upper lip & $3.88+1.23$ & $3.61+1.47$ & 0.905 \\
\hline 10. & Had trouble dealing with your weight & $4.17+1.55$ & $3.70+1.33$ & 0.224 \\
\hline 11. & Had low self esteem as aresult of having your pcos & $4.04+1.16$ & $3.52+1.34$ & 0.137 \\
\hline 12. & Felt frustration in trying to loose weight & $4.21+1.53$ & $3.57+1.41$ & 0.067 \\
\hline 13. & Felt afraid of not being able to have children & $3.38+1.58$ & $3.22+1.41$ & 0.866 \\
\hline 14. & Felt frightened of getting cancer & $3.04+1.04$ & $3.17+1.19$ & 0.765 \\
\hline 15. & Growth of visible hairon your face & $3.79+1.44$ & $3.13+1.14$ & 0.137 \\
\hline 16. & Embarrassment about excessive body hair & $3.38+1.31$ & $3.09+1.12$ & 0.504 \\
\hline 17. & Worried about having pcos & $4.04+1.23$ & $3.39+1.12$ & 0.085 \\
\hline 18. & Self conscious as a result of having pcos & $3.88+1.08$ & $3.52+1.12$ & 0.188 \\
\hline 19. & Abdominal bloating & $3.79+1.14$ & $3.17+1.15$ & 0.050 \\
\hline 20. & Late menstrual periods & $3.67+1.31$ & $3.87+1.29$ & 0.318 \\
\hline 21. & Menstrual cramps & $3.71+1.49$ & $3.35+1.19$ & 0.354 \\
\hline 22. & $\begin{array}{l}\text { Feel like you are not sexy because of being } \\
\text { overweight }\end{array}$ & $3.88+1.65$ & $3.35+1.37$ & 0.226 \\
\hline 23. & Feel a lack of control over the situation with pcos & $4.00+1.32$ & $3.48+1.12$ & 0.076 \\
\hline 24. & Have difficulties staying at your ideal weight & $4.17+1.46$ & $3.61+1.16$ & 0.090 \\
\hline 25. & Feel sad because of infertility problems & $3.46+1.38$ & $3.39+1.31$ & 0.096 \\
\hline 26. & Growth of visible body hair & $4.00+1.18$ & $3.39+1.34$ & 0.073 \\
\hline
\end{tabular}

Note: $\mathrm{P}$ value $\leq 0.05$ denotes significant effects and $\mathrm{P}$ value $\geq 0.05$ denotes no significant effects 


\section{JMSCR Vol||05||Issue||12||Page 31791-31800||December}

Figure 1 Demographic profile of patients with PCOS was recorded in the beginning of the trial

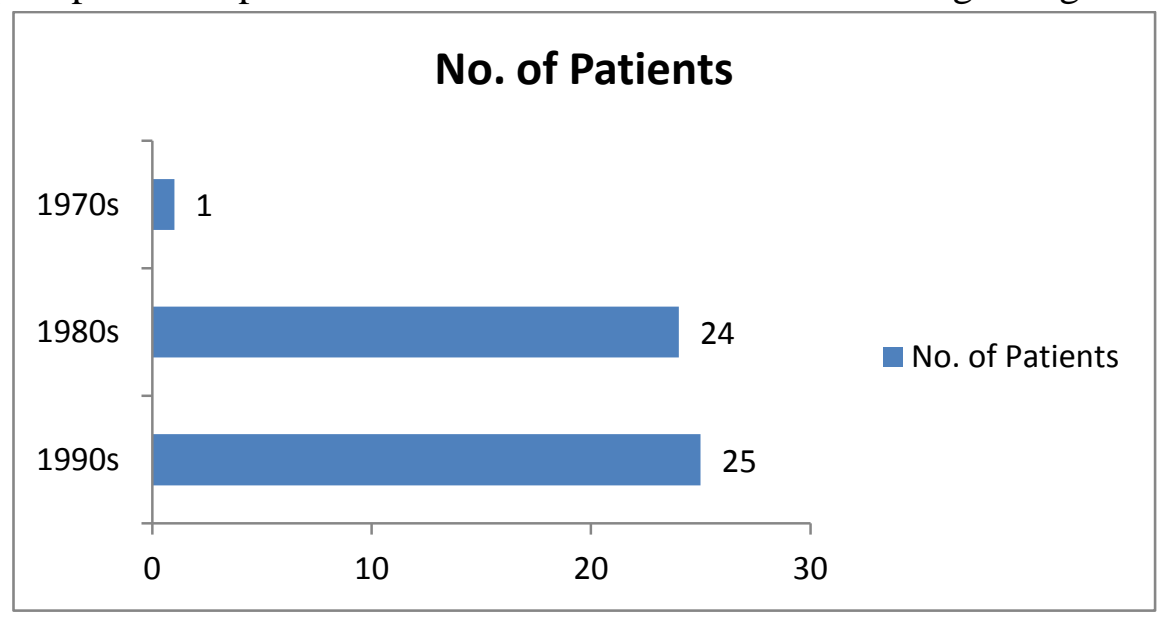

Figure 2 Marital status of the patients participated in the study

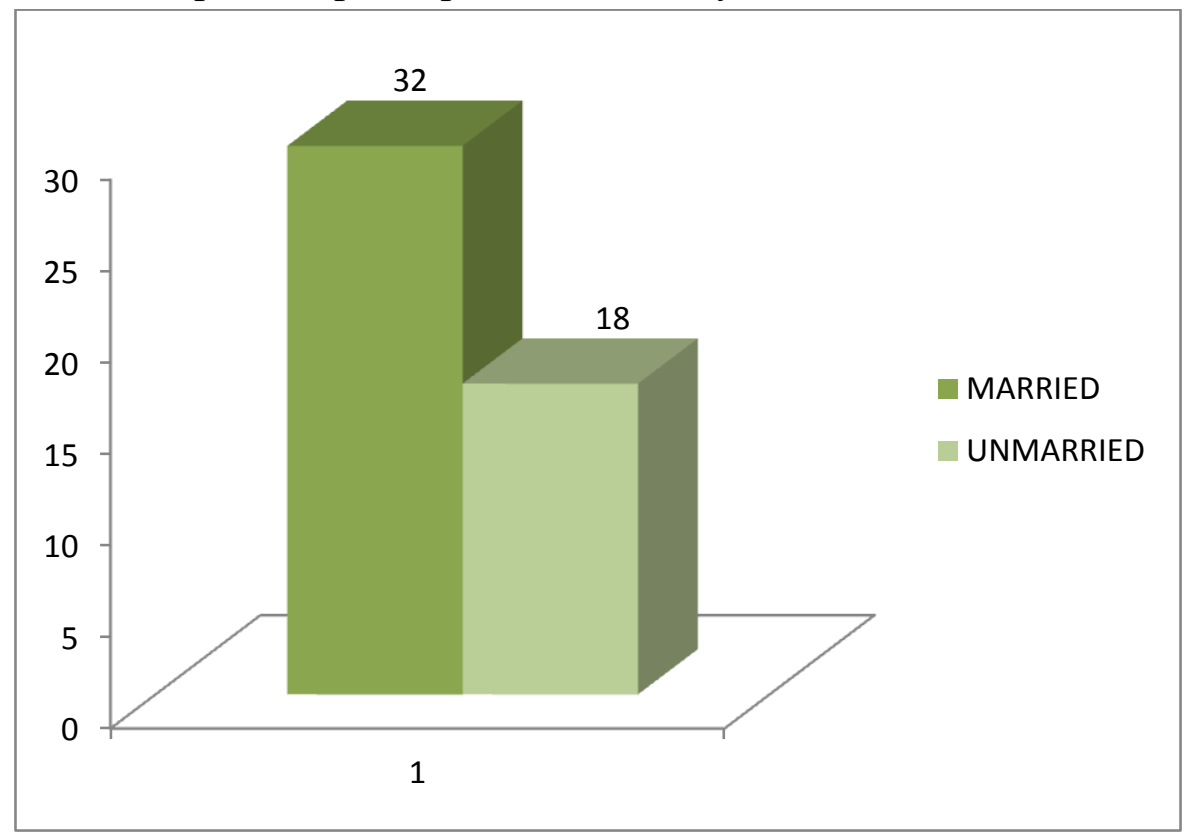

Figure 3 Body mass index (BMI) of the patients involved in the study

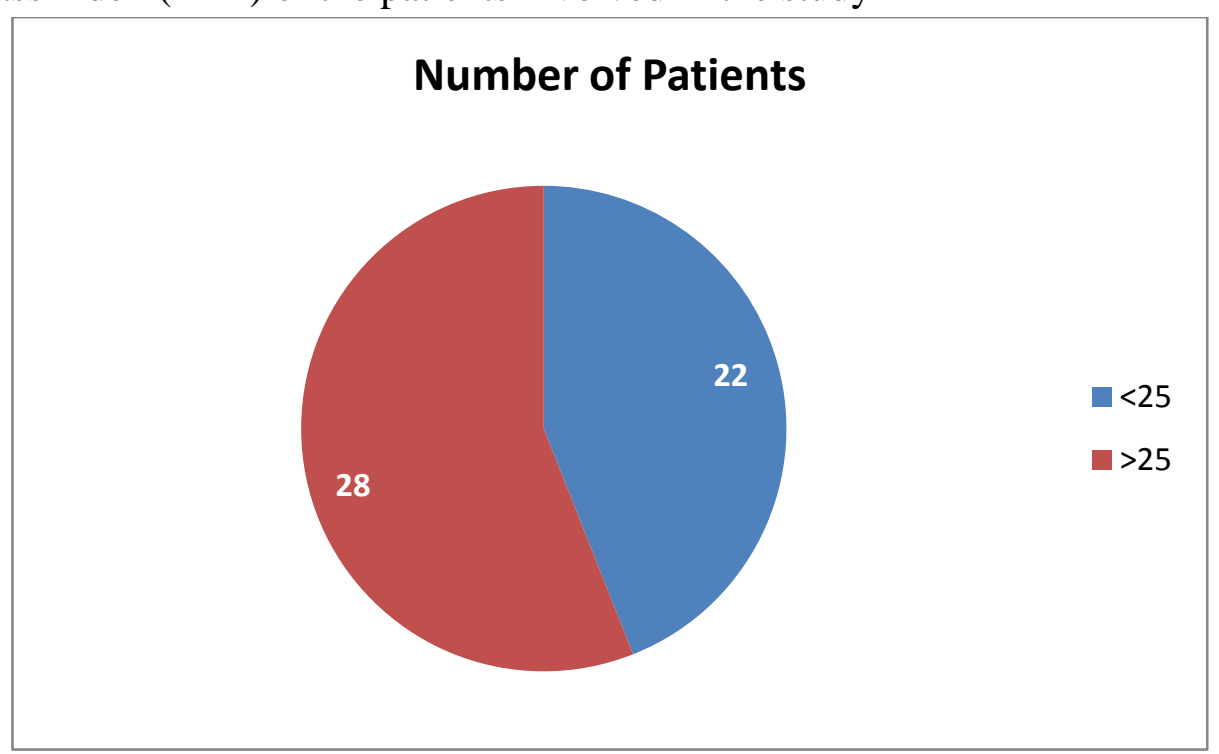


Figure 4 Educational qualification of the patients participated in the study

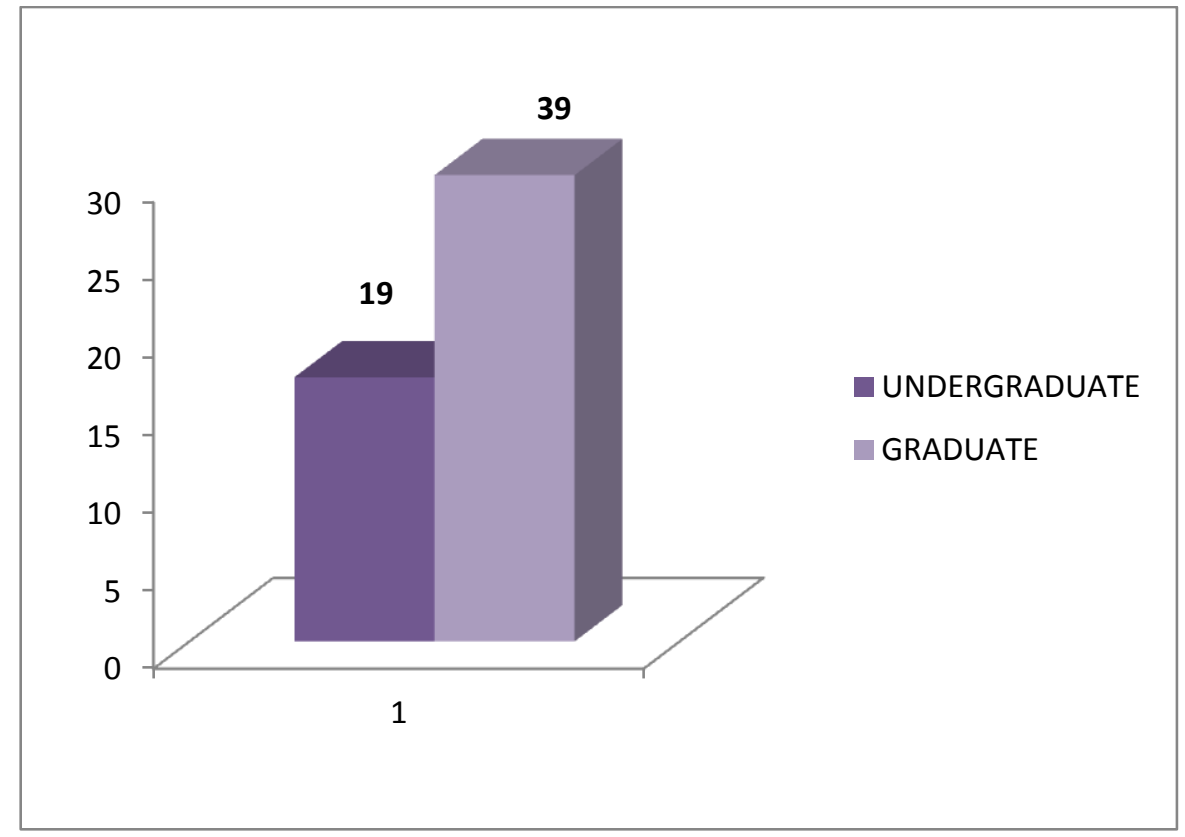

\section{Discussion}

The treatment of PCOS has been well established with OC pills ${ }^{5,22}$. The HRQL and emotional wellbeing improved significantly after metformin therapy in adult Women. ${ }^{23}$ However interventions like life style modification, weight reduction have also shown to improve quality of life in many studies. As it is known that insulin resistance is commonly associated with PCOS, some physician tried to use metformin as a treatment option. Though, actual mechanism is not known, in some studies it showed to improve symptomatology in the patients ${ }^{24,25}$. But in a recent study, it is revealed that Metformin might improve healthrelated quality of life of polycystic ovary syndrome women by ameliorating psychological disturbances due to acne, hair loss and infertility problems, especially for overweight and hyperandrogenic patients ${ }^{26}$. Previous research has supported that insulin sensitizers (e.g., metformin) provide fertility benefits to PCOS patients (i.e., improve pregnancy rate ${ }^{17}$, especially those with hyperinsulinemia or insulin resistance, which could be responsible for the abnormal ovarian response $^{27}$. Guyatt et al.'s study observed significant improvements in the infertility aspect of the PCOS-specific HRQoL (measured via PCOSQ) after 44 weeks of troglitazone treatment ${ }^{8}$. Troglitazone, an insulin sensitizer like metformin, was previously used in PCOS. The present study also observed improved infertility aspect of PCOS-specific HRQoL, especially in hyperandrogenic patients. Thus, the amelioration of ovulation problems achieved by insulin sensitizers (i.e., troglitazone, metformin) may alleviate emotional distress due to infertility and thus contribute to the improvement of the HRQoL of PCOS patients. The infertility domain in ChiPCOSQ consists of three items: "concerned about infertility problems", "afraid of not being able to have children", and "sad because of infertility problems". These items are associated with patient's psychological concerns about fertility. Although we did not find a significant increase in pregnancy rate in our reproductive-aged participants after treatment, however, patient's perceived benefits from metformin and reduced susceptibility to infertility after treatment ${ }^{28}$ may lead to the improved fertility aspect of HRQoL. Metformin is recommended as one of treatment options in PCOS women, especially for those who present obesity, hyperandrogenism, insulin resistance or hyperinsulinemia ${ }^{19}$. Consistently, our results showed significant effects of metformin on HRQoL of PCOS patients, especially in overweight and hyperandrogenic patients. Also, insulin resistance is one of important characteristics for metformin efficacy ${ }^{29}$. Our 
previous study showed that with metformin treatment, overweight PCOS women (BMI $\geq 25$ $\mathrm{kg} / \mathrm{m} 2$ ) had a significant reduction in body weight as compared to those with normal weight and patients with insulin resistance had a significantly improved 2-h insulin level as compared to those without insulin resistence ${ }^{20}$. In the present study, we found that the prevalence of insulin resistance in the overweight group was higher than that in the normal weight group (85 versus $58 \%$ ). This may be another reason why positive effect of metformin on HRQoL outcomes was observed in overweight patients, but not in normal weight patients. Moreover, it has been argued that the combination of menstrual problems, hyperandrogenism and anovulation can be positively affected by metformin treatment ${ }^{19}$. This may explain our findings showing that metformin provided significant benefits in HRQoL outcomes for PCOS women with hyperandrogenism, especially in terms of mitigating the burden of acne and hair loss, and infertility associated psychological distress on the HRQoL of patients. But in our study we did not find statistically significant additional benefit of metformin in patients with PCOS taking OC pills alone, suggesting the former has only placebo effect. Another explanation in support of our finding could be the short duration of our study and metformin might need a longer duration to show its beneficial effect. As a part of our study we also tried to validate the PCOSQ in Indian population. This can be a quantification method for response assessment in these patients and can help to objectively evaluate the symptomatology of them. Either due to small sample size or short duration of metformin therapy, the present study does not show any statistically significant result, but we can plan to extrapolate the study to achieve the target sample size in the present trail.

\section{Conclusion}

This study validated the PCOS questionnaire in Indian population which can be considered first of its kind. This can give us an objective method of response assessment in patients with PCOS.
This pilot study also showed that there is no significant additional effect of metformin on improvement of symptoms in patients with PCOS, this could be secondary to either small sample size or short duration of action. For authentication of the drug merformin for improvement of the symptoms related to PCOS, sample size should be more (1000) and minimum 6 months of therapeutic intervention.

\section{Reference}

1. Azziz R, Marin C, et al. Health carerelated economic burden of the polycystic ovary syndrome during the reproductive life span. J Clin Endocrinol Metab 2005;90:4650-8.

2. Nidhi R, Padmalatha V, et al Prevalence of polycystic ovarian syndrome in Indian adolescents. J Pediatr Adolesc Gynecol 2011;24:223-7.

3. Trent M, Rich M, et al Quality of life in adolescent girls with polycystic ovary syndrome. AMA. 2002; 156(6):556-560.

4. Pekhlivanov $B$, Kolarov $G$, et al Determininants of health related quality of life in women with polycystic ovary syndrome. Akusherstvo I Ginkekologiia. 2006; 45(7):29-34.

5. Yen SSC. The polycystic ovary syndrome. Clin Endocrinol (Oxf.) 1980;12:177-208.

6. Rotterdam ESHRE/ASRM-Sponsored PCOS Consensus Workshop Group: Revised 2003 consensus on diagnostic criteria and long-term health risks related to polycystic ovary syndrome. Fertil Steril 2004; 81:19-25.

7. Asuncion M, Calvo RM, San Millan JL, Sancho J, Avila S, Escobar-Morreale HF. A prospective study of the prevalence of the polycystic ovary syndrome in unselected Caucasian women from Spain. J Clin Endocrinol Metab. 2000;85:2434-8.

8. Guyatt G, Weaver B, Cronin L, Dooley JA, Azziz R. Health-related quality of life in women with polycystic ovary syndrome, a self-administered questionnaire, 
was validated. $\mathrm{J}$ Clin Epidemiol. 2004;57:1279-87.

9. Barnard L, Ferriday D, Guenther N, Strauss B, Balen AH, Dye L. Quality of life and psychological well being in polycystic ovary syndrome. Hum Reprod. 2007;22:2279-86.

10. Elsenbruch S, Hahn S, Kowalsky D, Öffner AH, Schedlowski M, Mann K, Janssen OE. Quality of life, psychosocial well-being, and sexual satisfaction in women with polycystic ovary syndrome. J Clin Endocrinol Metab. 2003; 88:5801-7.

11. Elsenbruch S, Benson S, Hahn S, Tan S, Mann K, Pleger K, Kimmig R, Janssen OE. Determinants of emotional distress in women with polycystic ovary syndrome. Hum Reprod. 2006;21:1092-9.

12. Lipton MG, Sherr L, Elford J, Rustin MHA, Clayton WJ. Women living with facial hair: the psychological and behavioral burden. J Psychosom Res. 2006;61:161-8.

13. Coffey S, Bano G, Mason HD. Healthrelated quality of life in women with polycystic ovary syndrome: a comparison with the general population using the Polycystic Ovary Syndrome Questionnaire (PCOSQ) and the Short Form- 36 (SF-36). Gynecol Endocrinol. 2006;22:80-6.

14. Schmid J, Kirchengast S, VytiskaBinstorfer E, Huber J. Infertility caused by PCOS-health-related quality of life among Austrian and Moslem immigrant women in Austria. Hum Reprod. 2004;19:2251-7.

15. Zhao Y, Qiao J. Ethnic differences in the phenotypic expression of polycystic ovary syndrome. Steroids. 2013;78:755-60.

16. Ou H-t, Wu M-H, Lin C-Y, Chen P-C. Development of Chinese Version of Polycystic Ovary Syndrome HealthRelated Quality of Life Questionnaire (Chi-PCOSQ). PLoS One. 2015; 10:e0137772.

17. Sivalingam VN, Myers J, Nicholas S, Balen AH, Crosbie EJ. Metformin in reproductive health, pregnancy and gynaecological cancer: established and emerging indications. Hum Reprod Update. 2014;20:853-68.

18. Nestler JE. Metformin for the treatment of the polycystic ovary syndrome. N Engl J Med. 2008;358:47-54.

19. Genazzani AD, Ricchieri F, Prati A, Chierchia E, Rattighieri E, Bosco G, Despini G, Campedelli A, Farinetti A, Santagni S. PCOS and metformin: from pharmacology to clinical use for women's health. Trial. 2012;12:14.

20. Ou H-t, Chen P-C, Wu M-H: Effect of metformin by employing 2-hour postload insulin for measuring insulin resistance in Taiwanese women with polycystic ovary syndrome. Journal of the Formosan Medical Association 2016.

21. Tang T, Glanville J, Hayden CJ, White D, Barth JH, Balen AH. Combined lifestyle modification and metformin in obese patients with polycystic ovary syndrome. A randomized, placebo

22. Trent ME, Rich M, Austin BS, Gordon CM. Fertility concerns and sexual behavior in adolescent girls with polycystic ovary syndrome implications for quality of life. J Ped and Adolesc Gyn 2003;16(1):33-7.

23. Hillard PJ Oral contraceptives and the management of hyperandrogenismpolycystic ovary syndrome in adolescents. Endocrinol Metab Clin North Am 2005; 34:707-723

24. Huber-Buchholz MM, Carey DG, et al Restoration of reproductive potential by lifestyle modification in obese polycystic ovary syndrome: role of insulin sensitivity and luteinizing hormone. J Clin Endocrinol Metab 1999; 84:1470-1474.

25. Hahn S, Benson S, Elsenbruch S, Pleger K, Tan S, Mann K, et al. Metformin treatment of polycystic ovary syndrome improves health-related quality of life, 
emotional distress and sexuality. Hum Reprod. 2006; 10:1093.

26. Cronin et al. Development of a healthrelated quality-of-life questionnaire (PCOSQ) for women with polycystic ovary syndrome (PCOS).J Clin Endo \& Met 1998;83(6):1976-87.

27. Miranda Harris-Glocker,. Kristin Davidson, et al. Improvement in qualityof-life questionnaire measures in obese adolescent females with polycystic ovary syndrome treated with lifestyle changes and oral contraceptives, with or without metformin Fertil Steril; 2010; 93:1016-13.

28. Ou HT, Chen PC, Wu MH, Lin CY. Metformin improved health-related quality of life in ethnic Chinese women with polycystic ovary syndrome. Health and quality of life outcomes. 2016 Aug 24;14(1):119. 